\title{
SIMULTANEOUS MEASUREMENT OF DEFORMATION AND TEMPERATURE OF HIGH-STRENGTH CONCRETE AT VERY EARLY AGE TO DETERMINE THE INITIAL AND THE FINIAL SETTING TIME
}

Shu-Ken Lin

Department of Civil Engineering, National Chung Hsing University, Taichung, Taiwan, R.O.C

Chung-Ho Huang

Department of Civil Engineering, Dahan Institute of Technology, Hualien, Taiwan, R.O.C.

Chao-Shun Chang

Department of Construction Engineering, National Kaohsiung First University of Science and Technology, Kaohsiung, Taiwan, R.O.C

Tsong Yen

Department of Civil Engineering, National Chung Hsing University, Taichung, Taiwan, R.O.C, tyen@dragon.nchu.edu.tw

Chung-Hao Wu

Department of Civil Engineering, National Chung Hsing University, Taichung, Taiwan, R.O.C

See next page for additional authors

Follow this and additional works at: https://jmstt.ntou.edu.tw/journal

Part of the Engineering Commons

\section{Recommended Citation}

Lin, Shu-Ken; Huang, Chung-Ho; Chang, Chao-Shun; Yen, Tsong; Wu, Chung-Hao; and Lin, Yiching (2010)

"SIMULTANEOUS MEASUREMENT OF DEFORMATION AND TEMPERATURE OF HIGH-STRENGTH CONCRETE AT VERY EARLY AGE TO DETERMINE THE INITIAL AND THE FINIAL SETTING TIME," Journal of Marine Science and Technology. Vol. 18: Iss. 2, Article 15.

DOI: $10.51400 / 2709-6998.2328$

Available at: https://jmstt.ntou.edu.tw/journal/vol18/iss2/15

This Research Article is brought to you for free and open access by Journal of Marine Science and Technology. It has been accepted for inclusion in Journal of Marine Science and Technology by an authorized editor of Journal of Marine Science and Technology. 
SIMULTANEOUS MEASUREMENT OF DEFORMATION AND TEMPERATURE OF HIGH-STRENGTH CONCRETE AT VERY EARLY AGE TO DETERMINE THE INITIAL AND THE FINIAL SETTING TIME

\section{Acknowledgements}

The authors are grateful for the financial supports from the Taiwan Power Company through a research project.

Authors

Shu-Ken Lin, Chung-Ho Huang, Chao-Shun Chang, Tsong Yen, Chung-Hao Wu, and Yiching Lin 


\title{
SIMULTANEOUS MEASUREMENT OF DEFORMATION AND TEMPERATURE OF HIGH-STRENGTH CONCRETE AT VERY EARLY AGE TO DETERMINE THE INITIAL AND THE FINIAL SETTING TIME
}

\author{
Shu-Ken Lin*, Chung-Ho Huang**, Chao-Shun Chang***, Tsong Yen*, \\ Chung-Hao $\mathrm{Wu}^{*}$, and Yiching Lin*
}

Key words: deformation, temperature, early age, setting time.

\begin{abstract}
The interior shrinkage deformation and temperature change of high-strength concrete (HSC) at very early age, i.e., the first $24 \mathrm{~h}$ from casting, and up to an age of $72 \mathrm{~h}$ was investigated experimentally using optic fibre sensors (SOFO) and thermally sensitive resistors. The initial and the final setting times of HSC were also investigated. Results show that two turning points (I and II) on the development curve of deformation, both represent the onsets of the variation of rigidity in fresh HSC, can be recognized as the initial and the final setting times, which are evaluated around $4.5 \mathrm{~h}$ to $5.7 \mathrm{~h}$ and $9.0 \mathrm{~h}$ to $11.8 \mathrm{~h}$, respectively. Also, the higher the fly-ash or silica fume replacement ratio, the longer the setting times. The setting times of HSC evaluated from the curve of temperature development are quite close to those measured from the deformation curve. In addition, the HSC setting times determined by penetration resistance method (ASTM C403) demonstrate unusually large values. This method is therefore not advised to be used to measure the setting times of HSC.
\end{abstract}

\section{INTRODUCTION}

A good knowledge about the mechanical properties and deformation behaviour of high-strength concrete (HSC) at

Paper submitted 02/04/09; revised 06/05/09; accepted 06/08/09. Author for correspondence: Tsong Yen (e-mail: tyen@dragon.nchu.edu.tw).

*Department of Civil Engineering, National Chung Hsing University, Taichung, Taiwan, R.O.C

**Department of Civil Engineering, Dahan Institute of Technology, Hualien, Taiwan, R.O.C.

***Department of Construction Engineering, National Kaohsiung First University of Science and Technology, Kaohsiung, Taiwan, R.O.C. very early age, which begins with pouring and ends with hardening, is essential. It can be very valuable in scheduling concrete construction operations, such as placing and removal of formwork during precast fabrication. The speed and quality of construction can thus be improved.

The chemical reaction of cement with water, namely hydration of cement, yields products that possess setting and hardening characteristics. Knowledge of the amount of released heat is important because it is sometimes a help and sometimes a hindrance. Similarly, the knowledge of reaction speed is important since it affects the times of setting and hardening. The initial setting must be slow enough to enable the concrete to be poured into place. In addition, after the concrete has been placed, rapid hardening, which refers to final setting time, is often desirable [2].

The deformation of HSC at very early age is still not well understood, mainly due to certain practical difficulties in carrying out experiments while the concrete is still in the plastic stage. For example, some conventional methods, such as those using electrical and mechanical strains gauges to measure the shrinkage deformation of fresh HSC, failed mostly because no gauge-points could be set-up before the concrete was hardened. On the other hand, some indirect methods to detect and predict the early age properties were used. Most of them were based on ultrasonic measurement $[1,7-9,11]$, calorimetric measurement $[7,11]$, and hydrostatic weighting $[1,11]$ of the specimens. By these methods the actual deformation was not directly measured, since they use indirect quantities, such as shear and compressive waves and the corresponding velocities, the rate of hydration, the activation energy and weight change, to deduce the mechanical properties.

By far, there are only few reports related with very early age deformation investigations using optic fibre sensors. These include low-coherence interferometers [3, 6], the use of FabryPerot interferometers [4], fibre Bragg gratings (FBGs) [12, 14] on cement paste [12] and unspecified types of concrete [3, 4]. 


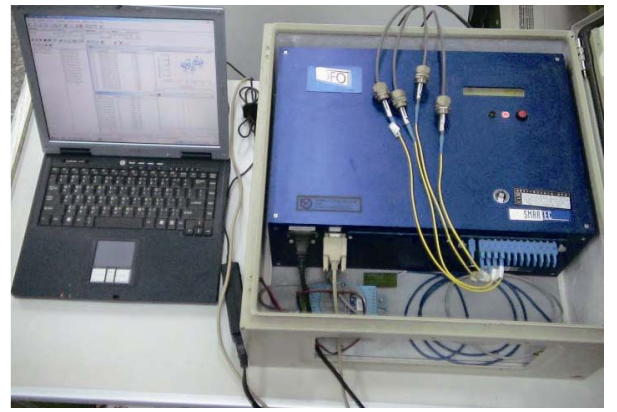

Fig. 1. SOFO measurement system.

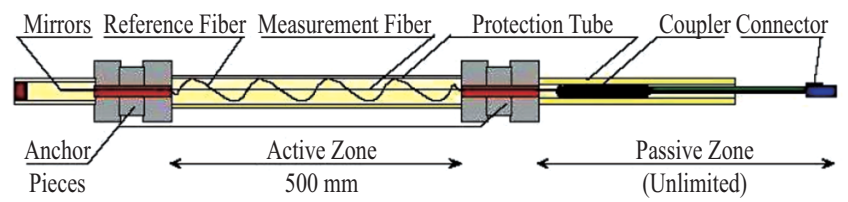

Fig. 2. Schema of SOFO sensor [5].

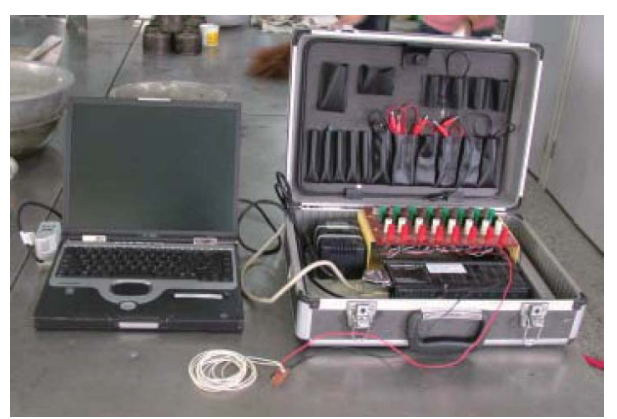

Fig. 3. Thermally sensitive detecting system.

In this paper, the deformation behaviour of HSC at very early age was investigated experimentally using a technique based on optic fibre sensors (SOFO) and thermally sensitive resistors. The technique was capable of multiplexing a number of sensors and resistors. All measurements were taken automatically, continuously and remotely. The interior shrinkage deformation and temperature change were detected simultaneously, immediately after casting and up to an age of 3 days. Moreover, the initial and the final setting times were also investigated from the deformation characteristics. By employing these techniques, it was attempted to have better understanding of HSC at very early age, and further to suggest a better experimental method to determine the setting times of concrete.

\section{MEASUREMENT SYSTEM}

\section{Deformation Measurement}

The SOFO deformation measurement system, developed by IMAC-EPFL [5, 13] was applied to measure the deformation of HSC at very early age. It included a portable reading unit,

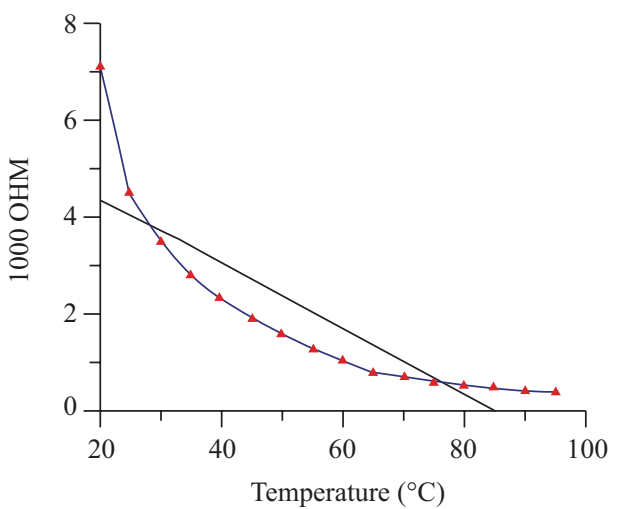

Fig. 4. Relations between electronic resistance and temperature.

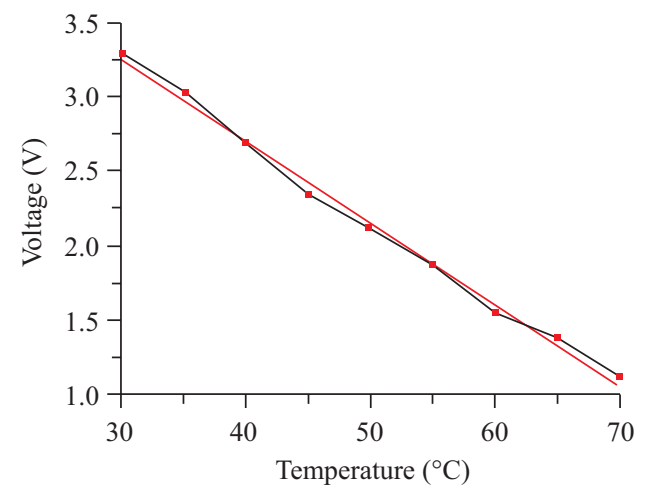

Fig. 5. Modified relations between voltage and temperature.

different types of fibre optic sensors and a software package, which allowed for the storage and computer aided analysis of a large number of measurements (see Fig. 1).

The SOFO sensor consists of two optical fibres (see Fig. 2): the measurement fibre and the reference fibre. The former is prestressed between the anchor pieces and followed its deformation. The later is independent of both the measurement fibre and the deformation of the structure. Any deformation of the structure will result in a change of the length difference between the two fibres. The usual length of the active zone of sensor is between $20 \mathrm{~cm}$ to $10 \mathrm{~m}$, so the SOFO system is well adapted to in situ applications.

\section{Thermal Detection}

A self-developed system of thermally sensitive detecting circuitry, as shown in Fig. 3, was adopted to continuously measure the internal thermal change of HSC. The thermally sensitive resistors (or thermistors) possessed a resistance- temperature characteristic that its interior resistance varied with the change of temperature. Nevertheless, the relation between the resistance and the temperature was non-linear (see Fig. 4). A Wheat-Stone bridge with compensation circuit was then applied to transform the resistance to voltages, and thus a linear relation between voltage and temperature can be obtained for better adjustment (see Fig. 5). 
Table 1. Mixture proportions of $\mathrm{HSC}\left(\mathrm{kg} / \mathrm{m}^{3}\right)$.

\begin{tabular}{|c|c|c|c|c|c|c|c|c|}
\hline Mixture & $\mathrm{W} / \mathrm{B}$ & Water & Cement & SF & FA & Fine aggregate & Coarse aggregate & $\mathrm{SP}$ \\
\hline W25S05F10 & \multirow{4}{*}{0.25} & \multirow{4}{*}{146} & 510 & 30 & 60 & 497 & 1138 & 6 \\
\hline W25S05F30 & & & 390 & 30 & 180 & 645 & 950 & 6 \\
\hline W25S15F10 & & & 450 & 90 & 60 & 654 & 963 & 6 \\
\hline W25S15F30 & & & 330 & 90 & 180 & 557 & 1015 & 6 \\
\hline
\end{tabular}
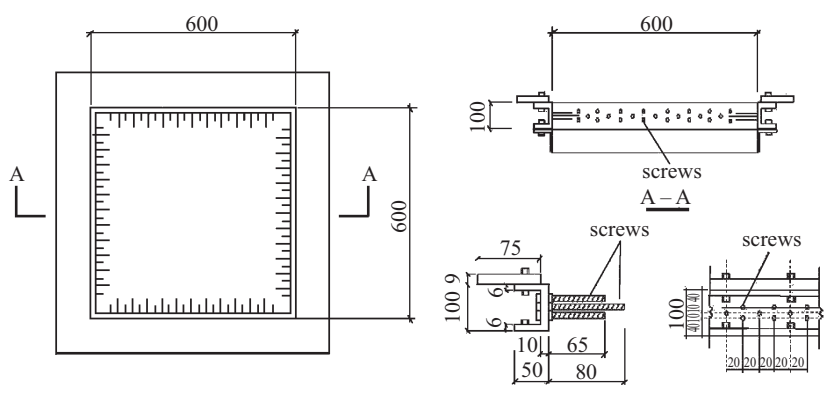

Fig. 6. Steel mould.
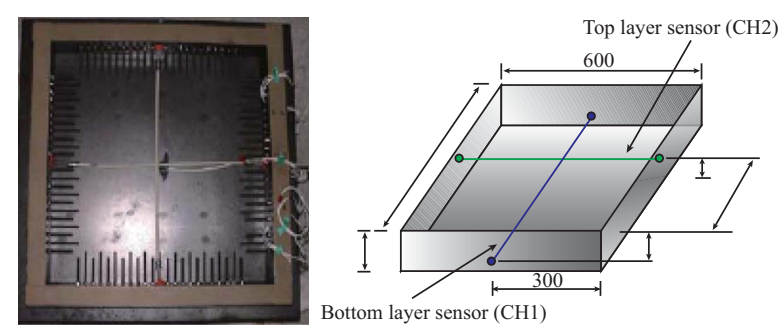

Fig. 7. Location of SOFO sensors in the specimen.

\section{EXPERIMENTS}

The test specimens of HSC were prepared with a mix proportion given in Table 1. The mix yields a water-to-binder ratio (W/B) of 0.25 , in which silica fume and fly-ash were used to replace part of cement by weight with $5 \%, 15 \%$ and $10 \%, 30 \%$, respectively.

The dimension of the slab specimens were $600 \mathrm{~mm} \times 600$ $\mathrm{mm} \times 100 \mathrm{~mm}$. They were formed by casting using an edge restrained steel mould (see Fig. 6). For the measurement of shrinkage deformation, two SOFO sensors run crosswise embedded at two different depths of specimens. As shown in Fig. 7, one (CH1) was placed $25 \mathrm{~mm}$ above the bottom surface of the specimen and the other $(\mathrm{CH} 2)$ was placed $25 \mathrm{~mm}$ under the top surface. In addition, at the center of the specimen, three thermistors of No. 1, 2 and 3 were embedded in the bottom, middle and top layers, respectively (see Fig. 8). Using these thermistors, one could measure the temperature development and distribution of specimens.

When the HSC mixture was ready, it was poured in two layers into the moulds while following the compaction of each half layer. Once the HSC specimens were cast, they were stored in a controlled room with a constant temperature of

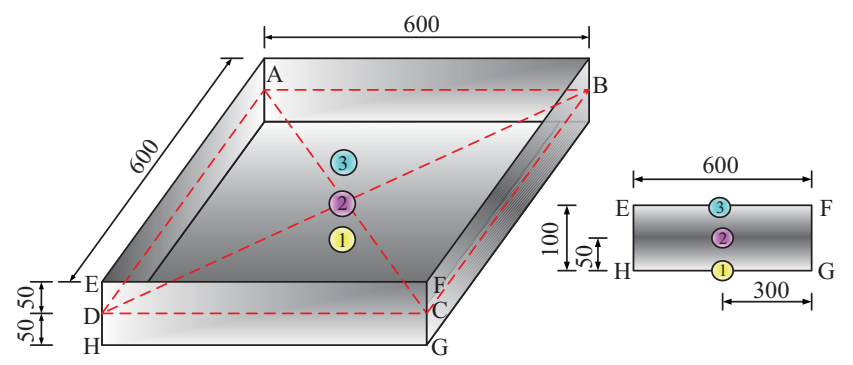

Fig. 8. Position of the embedded thermistors in the specimen.

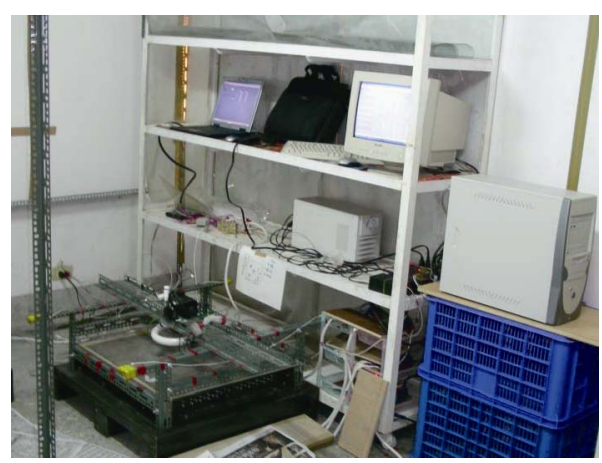

Fig. 9. Set-up of detecting equipment in a controlled room.

$23^{\circ} \mathrm{C}$ and a relative humidity of $50 \%$. All the specimens were left in the moulds throughout the whole measurement period. The shrinkage deformation and temperature were monitored immediately after the SOFO sensors and thermistors were connected to the measurement system. The final set-up in the controlled room, including the measurement and the detecting equipment, is shown in Fig. 9. In the experiments, the measurements with SOFO sensors and thermistors were set to aquire and record the data at every 5 and 3 minutes, respectively, and the data were transmitted to a personal computer for processing and analysis.

Besides the measurements of the shrinkage deformation and the temperature development of the slab specimens, a parallel test to measure the setting times of HSC mixture by penetration resistance using the procedures described in ASTM C403 was carried out on the same mix proportions of Table 1. The test results of the initial and the final setting times measured by penetration resistance method then provide a significant comparison. 


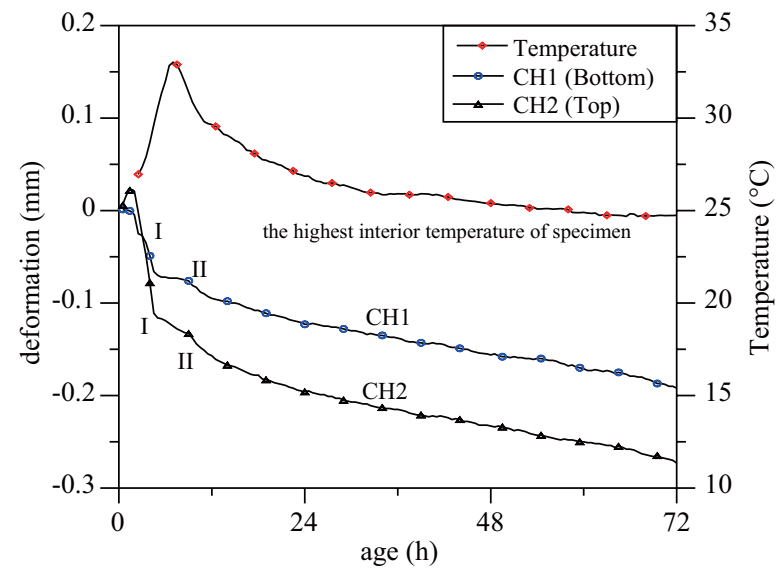

Fig. 10. Deformation development of specimen W25S15F10.

\section{RESULTS AND DISCUSSION}

\section{Deformation and Temperature Development of HSC after Casting Up to 3 Days}

Since the HSC specimens were put in a controlled room at $23^{\circ} \mathrm{C}$ and $50 \%$ R.H., the early age deformation was mainly composed of autogeneous shrinkage, thermal deformation (swelling and shrinkage) and drying shrinkage. The sum of deformation was measured using the SOFO sensor during an age of 3 days. The evolution of the deformations of specimen $\mathrm{W} 25 \mathrm{~S} 15 \mathrm{~F} 10$, as an example, during the period is presented in Fig. 10. The figure indicates that the deformation increases steadily at the beginning after casting and lasts only a short period. This initial heat deformation ceases quickly, making the curve turn to flat and descending from point I to point II. After point II, the curve tends to become relatively flatter due to monotonic shrinkage. In the figure, both point I and point II represent the onsets of the variation of rigidity in fresh HSC. Point I indicates the stiff state of concrete, turning from true fluidity to plasticity. On the other hand, point II represents a beginning of hardening that the mechanical strength starts to develop.

In addition to the deformation measurement, the internal temperature developments of specimens were simultaneously investigated by thermistors No. 1 (bottom), No. 2 (middle) and No. 3 (top). Since all specimens exhibited a similar temperature development, the result from the middle thermistor (No. 2), which had the highest temperature to evaluate the temperature change, was adopted. Figure 11 illustrates the temperature development of all the specimens. The figure shows that the interior temperature of specimens after casting kept increasing with a momentary slowing down. The temperature reaches a peak, which corresponds with the maximum rate of heat evolution. By this time, final set has been passed and early hardening has begun. Based on the temperature curve, the final setting time can be determined as the instant when the temperature reaches the maximum [12], which is around $7 \mathrm{~h}$ to $9 \mathrm{~h}$ after casting.

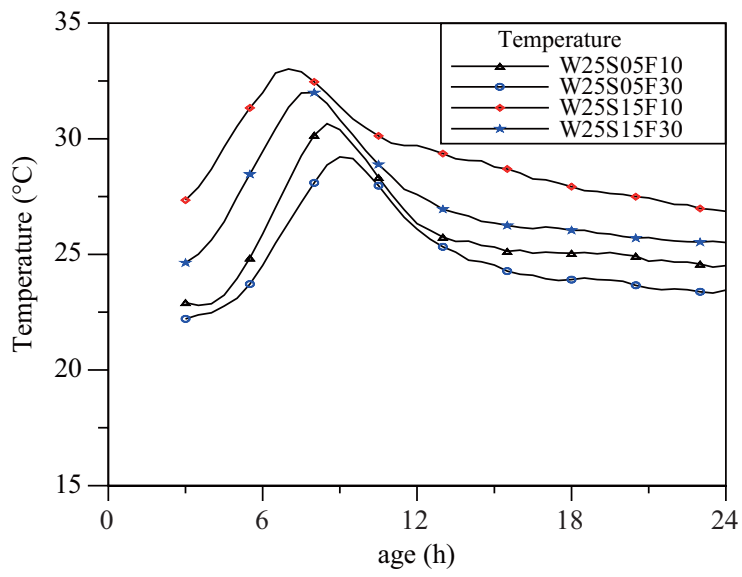

Fig. 11. Temperature development of HSC.

\section{Evaluation of Setting Time}

Setting of concrete is defined as the onset of solidification in a fresh concrete mixture. Till now, both the initial and the final setting times of concrete are arbitrarily defined by a test method as the penetration resistance (ASTM C403). However, it does not make a specific change in the physical-chemical characteristics of the cement paste. They are purely functional point in the sense that the former represents approximately the limit of handling and the later represents approximately the time after which strength begins to develop. Accordingly, the initial and the final setting times imply respectively the turning points of the stiffness state of concrete.

Figure 12 indicates the deformation evolution of all specimens during the first 24 hours. One can find two turning points (I and II) on each curves, which represent the stiffness change from plastic state to beginning of solidification and from complete solidification to beginning of hardening, respectively. At points I and II can be found a deformation rate change or a slope change of curve. As the point I corresponds to the initial setting time and the point II corresponds to the final setting time, the results of all the specimens are shown in Table 2, in which the initial setting times vary from $4.6 \mathrm{~h}$ to $5.7 \mathrm{~h}$ and the final setting times are from $9.2 \mathrm{~h}$ to $11.8 \mathrm{~h}$ respectively.

According to the concept from the previous study [10], the heat peak represents the heat of formation of ettringite. It is believed that the heat evolution period includes some heat of solution due to $\mathrm{C}_{3} \mathrm{~S}$ and heat of formation of $\mathrm{CSH}$. The paste of properly retarded cement will retain much of its plasticity before the commencement of this heat cycle and will stiffen and show the initial set before reaching at the apex of curve, which corresponds to the final set. As such, from Fig. 11 the point I and II may be found to be corresponding with the initial and final setting time, respectively, of all specimens. The results can be evaluated as given in Table 2, in which the initial setting times are from $2.8 \mathrm{~h}$ to $4.3 \mathrm{~h}$ and the final setting times are from $7.0 \mathrm{~h}$ to $8.8 \mathrm{~h}$. These values of result do not completely coincide with those determined from the deformation evolution curves 

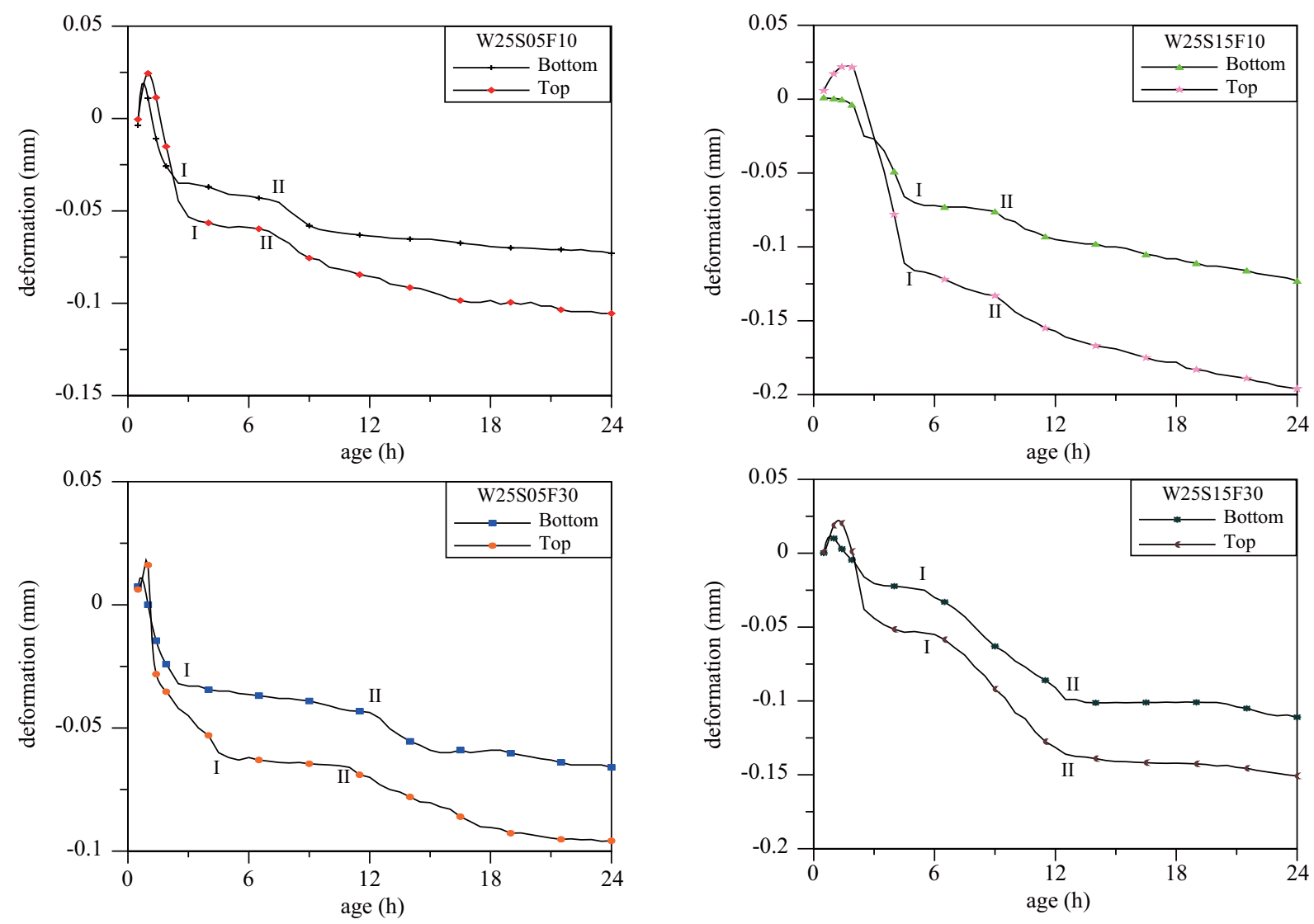

Fig. 12. Deformation development of HSC.

Table 2. Comparison of setting time of HSC by various methods.

\begin{tabular}{|c|c|c|c|c|c|c|}
\hline \multirow{2}{*}{ Mixture } & \multicolumn{3}{|c|}{ Initial setting time $(\mathrm{h})$} & \multicolumn{3}{c|}{ Final setting time (h) } \\
\cline { 2 - 7 } & by temperature & by deformation & by penetration & by temperature & by deformation & by penetration \\
\hline W25S05F10 & 4.0 & 3.7 & 17.5 & 8.3 & 7.3 & 22.2 \\
\hline W25S05F30 & 4.3 & 4.8 & 23.2 & 8.8 & 9.8 & 28.2 \\
\hline W25S15F10 & 2.8 & 4.6 & 12.2 & 7.0 & 9.2 & 14.6 \\
\hline W25S15F30 & 3.1 & 5.7 & 17.5 & 7.6 & 11.8 & 21.0 \\
\hline
\end{tabular}

of Fig. 12. However, the differences appear relatively small and acceptable, since the deviation of the initial setting time varies from $0.3 \mathrm{~h}$ to $2.5 \mathrm{~h}$, and $1 \mathrm{~h}$ to $4 \mathrm{~h}$ for the final setting time. Moreover, it can be found in Table 2 that the initial and the final setting times of HSC with higher fly-ash or silica fume replacement ratio demonstrate longer periods. This may be attributed to the reduction of cement content in concrete, causing a decrease of hydration heat and the setting effect.

\section{Comparison of the Test Results of Setting Time with the Method of ASTM C403}

The parallel tests for the measurement of the setting times of HSC by penetration resistance of ASTM C403 were carried out and the results are shown in Table 2. It shows that both the initial and the final setting times determined by the proposed method of deformation change agree rather well with the results from Fig. 11. The relative differences are mostly under $150 \%$. In contrast, the discrepancy between the results of the new method and those of penetration resistance method (ASTM C403) is relatively large. The initial and the final setting times of all specimens obtained from penetration resistance method are $200 \%$ to $500 \%$ larger than those from the new method. To explore the reason why there is such variation, we vertically cut the specimens of penetration resistance test and observed the surface profile (see Fig. 13). A non-uniform mixture was found on the cutting surface, of which the upper layer of mortar seemed rich in mineral paste, while the coarse sand dispersed to bottom layer. This lead to weakness, porosity and lacking of strength or penetration resistance, and resulted in an incorrect determination of longer setting times. 


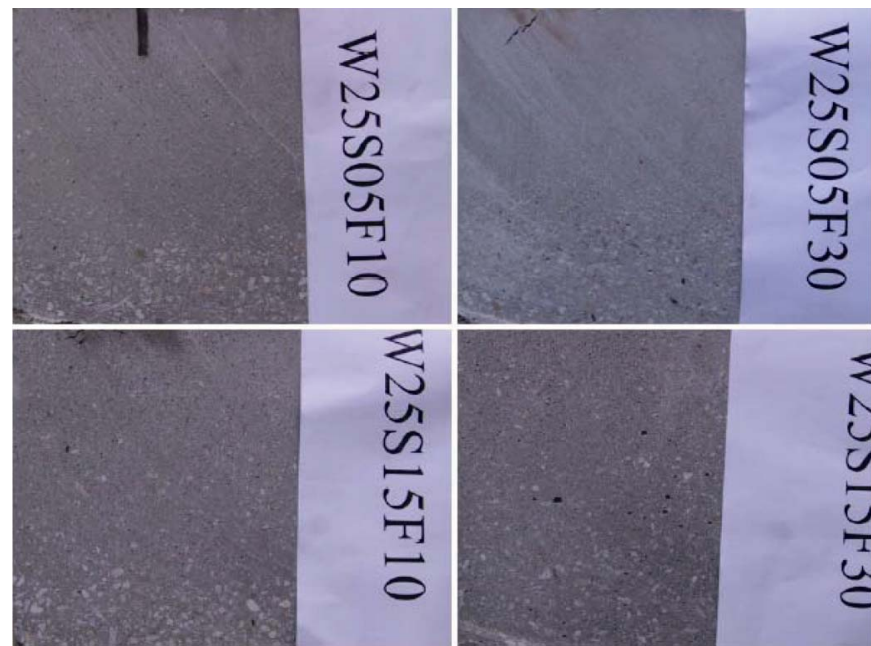

Fig. 13. Dispersion of mortar obtained on the cutting surface of the specimen of penetration resistance test.

\section{CONCLUSION}

By using a technique based on optic fibre sensors (SOFO) and thermally sensitive resistors, it is possible to detect the interior shrinkage deformation and the temperature change of high strength concrete at very early age. According to the test results, several conclusions are drawn as fellows:

1. The measurement of using SOFO sensors to detect the deformation of HSC evolved at very early age (3 days), presented in Fig. 10, can be used to interpret two turning points (I and II), which represent the onsets of the variation of rigidity in fresh HSC.

2. According to the definition of setting time of concrete, the initial and the final setting times indicates respectively the turning points (I and II) of the stiffness state of HSC. Thus, the turning point I can be recognized as initial setting time and turning point II as the final setting time of HSC, which are from $4.6 \mathrm{~h}$ to $5.7 \mathrm{~h}$ for initial setting time and $9.2 \mathrm{~h}$ to $11.8 \mathrm{~h}$ for final setting time, respectively. Moreover, an increase of the replacement ratio of fly-ash or silica fume can increase both of the setting times of HSC.

3. The initial and the final setting times of HSC evaluated from the curve of temperature development (Fig. 11) are around $2.8 \mathrm{~h}$ to $4.3 \mathrm{~h}$ and $7.0 \mathrm{~h}$ to $8.8 \mathrm{~h}$, respectively.

4. The setting times of HSC determined by penetration resistance method (ASTM C403) demonstrate unusual values due to dispersion of mortar mixture. Therefore, this test method is not suggestive to evaluate the initial and the final setting time of HSC.

\section{ACKNOWLEDGMENTS}

The authors are grateful for the financial supports from the Taiwan Power Company through a research project.

\section{REFERENCES}

1. Boumiz, A., Vernet, C., and Cohen Tenoudji, F., "Mechanical properties of cement pastes and mortars at early ages: Evolution with time and degree of hydration," Advanced Cement Based Materials, Vol. 3, No. 3-4, pp. 94-106 (1996).

2. Brunauer, S., and Copeland, L. E., "The chemistry of concrete," Scientific American, Vol. 210, No. 4, pp. 80-92 (1964).

3. Glisic, B. and Simon, N., "Monitoring of concrete at very early age using stiff SOFO sensor," Cement \& Concrete Composites, Vol. 22, No. 2, pp. 115-119 (2000).

4. Habel, W. R., Hofmann, D., and Hillemeier, B., "Deformation measurements of mortars at early ages and of large concrete components on site by means of embedded fiber-optic microstrain sensors," Cement \& Concrete Composites, Vol. 19, No. 1, pp. 81-102 (1997).

5. Inaudi, D., Fibre Optic Sensor Network for the Monitoring of Civil Engineering Structure, Thesis No. 1612, Swiss Federal Institute of Technology, Lausanne, Switzerland (1997).

6. Inaudi, D., Vurpillot, S., Casanova, N., and Osa-Wyser, A., "Development and field test of deformation sensors for concrete embedding," Smart Structures and Materials, SPIE Vol. 2721, San Diego, California, USA. (1996).

7. Krau $\beta$, M. and Hariri, K., "Determination of initial degree of hydration for improvement of early-age properties of concrete using ultrasonic wave propagation," Cement \& Concrete Composites, Vol. 28, No. 4, pp. 299-306 (2006).

8. Lacouture, J. C., Johnson, P. A., and Cohen Tenoudji, F., "Study of critical behavior in concrete during curing by application of dynamic linear and nonlinear means," Journal of Acoustical Society of America, Vol. 113, pp. 1325-1332 (2003).

9. Loukili, A., Chopin, D., Khelidj, A., and Le Touzo, J. Y., "A new approach to determine autogenous shrinkage of mortar at an early age considering temperature history," Cement and Concrete Research, Vol. 30, No. 6, pp. 915-922 (2000).

10. Mehta, P. K., Concrete, Prentice-Hall, Englewood Cliffs, N. J. (1986).

11. Morin, V., Cohen Tenoudji, F., Feylessoufi, A., and Richard, P., "Evolution of the capillary network in a reactive powder concrete during hydration process," Cement and Concrete Research, Vol. 32, No. 12, pp. 1907-1914 (2002).

12. Slowik, V., Schlattner, E., and Klink, T., "Experimental investigation into early age shrinkage of cement paste by using fibre Bragg gratings," $\mathrm{Ce}$ ment \& Concrete Composites, Vol. 26, No. 5, pp. 473-479 (2004).

13. Vurpillot, S., Inaudi, D., and Ducert, J. M., "Bridge monitoring by fibre optics deformation sensors: design, emplacement and results," Smart Structures and Materials, SPIE, Vol. 2719, San Diego, California, USA. (1996).

14.Wong Allan, C. L., Childs Paul, A., Berndt, R., Macken, T., Peng, G. D., and Gowripalan, N., "Simultaneous measurement of shrinkage and temperature of reactive powder concrete at early-age using fibre Bragg grating sensors," Cement \& Concrete Composites, Vol. 29, No. 6, pp. 490-497 (2007). 